\title{
Family planning program of Bangladesh: Achievements and challenges
}

Tapash Ranjan Das

Assistant Professor, Department of Community Medicine, Sheikh Sayera Khatun Medical College, Gopalganj, Bangladesh.

Bangladesh has made remarkable and rapid progress in many family planning and other health indicators. ${ }^{1}$ Two distinguish approaches of this program that contributed to rapid progress are the involvement of private sector and change in care seeking behavior of the people more towards facility. According to BDHS 2014, Bangladesh has achieved substantial success to increase in CPR to $62 \%$ and reduction of TFR to 2.2 per woman in last 10 years. ${ }^{2}$ Despite this progress, unmet need for family planning is still $12 \%$ among currently married woman and all method discontinuation rates is $30 \%$ within 12 month of starting. ${ }^{2}$

Once the only source of all modern contraceptive methods, public sector now stands at $49 \%$ in providing these contraceptives. ${ }^{2}$ Private and NGO sectors in Bangladesh are also the major suppliers of contraceptives to the women. ${ }^{3}$ This does not reflect the weaknesses in the Government Family Planning Programs rather peoples preference of anonymity in collecting the contraceptive methods. In-depth analysis of method mix in last ten year from 2004 to 2014 reveal that there is marked increase in share in use of condom and DMPA (depot medroxyprogesterone acetate) injectable which is available in private shops, pharmacies and doubled the use of Implant reflects the increase in service utilization from the public sector. ${ }^{2}$ Most striking feature of static share in IUD and male and female sterilization in last ten years reflect the target oriented work of family planning workers.

The government is trying to change in this method mix more towards long acting and reversible contraceptives and permanent methods. For this, new strategies have been implemented which included post partum family planning and involvement of obstetricians in family planning program. ${ }^{4}$ These strategies necessitate a shift in paradigm of family planning services more towards strengthening maternal health care services.

The BDHS 2014 showed at least one antenatal care (ANC) from a medically trained provider was $63.9 \%$ and skilled assistance at delivery was $42.1 \%$ increased from $15.6 \%$ in $2004 .^{2}$ Moreover, doctors are the major service providers during pregnancy and child birth next to the nurse/paramedics. It was noted that $37 \%$ of births were delivered at a health facility and $63 \%$ were delivered at home. Moreover, $84.8 \%$ of lowest wealth quintiles still prefer delivery at home and assumed that maternal mortality is highest in these quintiles.

It appears that public facilities are mostly preferred by the lower wealth quintile peoples but the awareness and confidence to quality of care in public sector still very low among these peoples particularly in rural areas.

The Government of Bangladesh has decentralized health care facilities more towards the rural community to ensure better access to maternity and family planning services. Community Clinic for every six thousand populations and Union Health and Family Welfare Centre are well equipped with trained manpower and adequate logistic supplies. Moreover, there are provisions for 3.3 community health workers per 10,000 populations. ${ }^{5}$ Despite all these, health service indicator shows insufficient access to and utilization of maternity and family planning services. ${ }^{1}$

Considering the above mentioned facts, Family Planning Programs should focus on registering 'Target Couple' and segment client to those who belong to lower wealth quintiles. This approach can taper down the number of couples field worker need to identify for maternity care and family planning services. Moreover, counseling for family planning should begin at the time of providing antenatal care.

Two thing need to be strengthened to overcome the barriers in seeking skilled care: one is the effective counseling in developing demand and the other is quality antenatal care. For this there should have appropriate job aid and standard operating procedures for the field workers and service providers.

The Ministry of Health and Family Welfare of Bangladesh is now formulating the next sector program for five years. This should be in light of United Nations' Sustainable Development goals, targets and indicators. ${ }^{6}$ On the pathway to low-middle income country, policy makers will face challenges in reducing the maternal mortality ratio to less than 100 per 100,000 live births and ensuring universal access to sexual and reproductive health care services which include family planning.

Researcher has shown that up to one-third of maternal death could be averted through the use of effective contraception by women wishing to postpone or cease further childbearing. ${ }^{7}$ According to United Nations estimation, Bangladesh will have population size of 186 million by the year $2030 .^{8}$ This estimates forecast future program need to deal with more women of reproductive age. Efficient management of service providers and facilities to redesign existing program can able to better address the future need and ensure universal access to health care to marginalized and vulnerable population.

Correspondence: Dr. Tapash Ranjan Das, Assistant Professor, Department of Community Medicine, Sheikh Sayera Khatun Medical College, Gopalganj, Bangladesh. E-mail: trdasbd@yahoo.com. 


\section{References}

1. Majumder MAA. World Health Statistics 2011: How does Bangladesh compare with other South -East Asian countries? South East Asia J Public Health 2011;1:4-11.

2. National Institute of Population Research and Training (NIPORT), Mitra and Associates, and ICF International. Bangladesh Demographic and Health Survey 2014. Dhaka, Bangladesh, and Rockville, Maryland, USA: NIPORT, Mitra and Associates, and ICF International, 2016.

3. Streatfield PK, Kamal N. Population and family planning in Bangladesh. J Pak Med Assoc 2013 ;63(4 Suppl 3):S73-81.

4. Directorate General of Family Planning (DGFP). Clinical Contraception Service Delivery Program Operation Plan, DGFP, 2011-16. Dhaka: DGFP, 2011.
5. El Arifeen S, Christou A, Reichenbach L, Osman FA, Azad K, Islam KS, et al. Community-based approaches and partnerships: innovations in health-service delivery in Bangladesh. Lancet 2013;382(9909):2012-26.

6. United Nations. Transforming our World: The 2030 Agenda for Sustainable Development. New York: United Nations, 2015.

7. Ali M, Seuc A, Rahimi A, Festin M, Temmerman M. A global research agenda for family planning: results of an exercise for setting research priorities. Bull World Health Organ 2014;92:93-8.

8. United Nations, Department of Economic and Social Affairs, Population Division. World Population Prospects: The 2015 Revision, Key Findings and Advance Tables. Working Paper No. ESA/P/WP.241. New York: United Nations, 2015. 